\title{
Implementasi Kebijakan Program Relawan Demokrasi oleh KPU Kota Padang Pada Pilkada 2018
}

\author{
Kurnia Harianto, Al Rafni \\ Program Studi Pendidikan Pancasila dan Kewarganegaraan \\ Universitas Negeri Padang \\ E-mail: harrykane085@gmail.com
}

\begin{abstract}
ABSTRAK
Jumlah pemilih pada pemilihan umum (Pemilu) pascareformasi cenderung menurun. Realita tersebut membuat Komisi Pemilihan Umum (KPU) mengambil kebijakan Relawan Demokrasi (Relasi) yang pengelolanya berada di KPUdi level Kota atau Kabupaten. Tujuan utama dari kebijakan Relawan Demokrasi adalah meningkatkan partisipasi pemilih. Di Kota Padang, kebijakan Program tersebut dinilai berhasil. Ini dapat dilihat dari partisipasi pemilih pada pilkada 2013 yang hanya sekitar 52\%, menurun dari pilkada 2008 dimana tingkat partisipasi masyarakat Kota Padang sekitar 56\% dan kemudian pada pilkada 2018 di mana terdapat kebijakan Relawan Demokrasi tingkat partisipasi masyarakat naik $12 \%$ dengan tingkat partispasi 64\%. Hal tersebut dapat secara ilmiah diteliti tentang bagaimana implementasi program relawan demokrasi oleh KPU pada Pilkada Kota Padang 2018 jika dilihat dari faktor-faktor keberhasilannya. Metode penelitian yang menggunakan pendekatan deskriptifkualitatif. Hasil penelitian didapat bahwa implementasi kebijakan program relawan demokrasi di KPU pada Pilkada Kota Padang terdapat faktor keberhasilan seperti komunikasi yang sudah efektif, sumber daya relawan demokrasi yang mencukupi, walaupun anggaran nya terbatas, disposisi, dimana para relawan demokrasi memiliki komitmen yang kuat untuk menjalankan program ini, dan struktur birokrasi, Kpu memiliki standar operasional (SOP) dan tugas pokok yang jelas. Tujuan penelitian adalah sebagai salah satu evaluasi dalam kebijakan yang diambil KPU dalam meningkatkan partisipasi pemilih dalam pemilu.
\end{abstract}

\section{Kata Kunci : Implementasi, Relawan Demokrasi, Pilkada}

\section{ABSTRACT}

The number of voters in the elections post reform tends to decline. The reality has made the General Election Commission (KPU) take the policy of democracy Volunteers (relationships) that the management is located in the city level or districts. The main objective of the volunteer democracy policy is increasing voters participation. In Padang City, the Program policy is assessed successfully. This can be seen from voters ' participation in the 2013 election which is only about 52\%, declining from the local 2008 elections where the community participation rate of Padang is around 56\% and then at the election 2018 where there is a policy of volunteer democracy level Community participation increased by 12\% with a participatory rate of $64 \%$. It can be scientifically researched about how the implementation of the program of Democratic volunteers by the KPU in Padang city elections 2018 if viewed from the factors of success. The research method uses a qualitative descriptive approach. The results of the research gained that the implementation of the policy of Democratic Volunteer Program in KPU in Padang city elections there are factors of success such as effective communication, the resources of adequate democratic volunteers, even 
though the budget is limited, Disposition, where the volunteers of democracy have a strong commitment to run the program, and the bureaucracy structure, KPU has operational standards and a clear principal task. The purpose of the study was as one of the evaluations in the policy of KPU to increase voters participation in the elections.

Keywords: Implementation, Democracy Volunteers, Election 2018

\section{PENDAHULUAN}

Demokrasi secara umum adalah sistem pemerintahan dengan memberikan kesempatan kepada seluruh warga negara dalam pengambilan keputusan. Dimana keputusan itu akan berdampak bagi kehidupan seluruh rakyat. Arti lainnya adalah rakyat bertindak sebagai pemegang kekuasaan tertinggi. Dalam melakukan tindakan politik seperti pemilu di harapkan rakyat menggunakan hak memilihnya dan berpartisipasi secara optimal. Salah satu upaya yang dilakukan oleh KPU dalam meningkatkan partisipasi politik adalah melalui sosialisasi Pemilu dengan membentuk Relawan Demokrasi.

Relawan Demokrasi adalah gerakan sosial yang dimaksudkan untuk meningkatkan partisipasi dan kualitas pemilih dalam menggunakan hak pilih. Program ini melibatkan peran serta masyarakat yang seluasluasnya dimana mereka ditempatkan sebagai pelopor (pioneer) demokrasi bagi komunitasnya.

Demokrasi sering dimaknai secara prosedural yaitu keberhasilan mengadakan pemilu. Salah satu indikator suksesnya pemilu adalah tingginya tingkat partisipasi pemilih. Di Indonesia dari pemilu masa reformasi sampai dengan saat ini, kecendrungan tingkat pemilih masyarakatnya masih rendah, bahkan cenderung semakin menurun dari tahun ke tahun.
Pada pemilu 1999 tingkat partispasi pemilih mencapai 92,6 persen dan jumlah golput 7,3 persen. Angka partisipasi yang memprihtinkan terjadi pada pemilu 2004, yakni turun hingga 84,1 persen dan jumlah golput meningkat 15,9 persen. Pada pemilu 2009 tingkat partisipasi politik semakin menurun yaitu hanya mencapai 70,9 persen dan jumlah golput semakin meningkat yaitu 29,1 persen, Pada pemilu 2014 tingkat partisipasi politik 75,2 persen sementra yang tidak menggunaan hak pilihnya mencapai 24,8 persen, Tingkat partisipasi pada tahun 2014 lebih tinggi sekitar 5 persen dari pemilu sebelumnya.

Salah satu upaya untuk meningkatkan partisipasi memilih dan mengantisipasi jumlah golput yang semakin banyak maka sejak Pemilu 2014, Komisi Pemilihan Umum (KPU) meluncurkan program bernama "Relawan Demokrasi". Program ini diterapkan di seluruh Kabupaten/Kota di Indonesia, termasuk di Kota Padang yang dinamakan dengan Relawan Demokrasi Kota Padang. Sesuatu yang perlu jadi perhatian khusus ialah bahwa kebanyakan anggota Relawan Demokrasi di Padang adalah pemuda. Padahal kaum muda adalah salah satu penyumbang besar meningkatnya angka golput di Indonesia.

Kecenderungan masyarakat Padang untuk memberikan hak pilih masih tergolong rendah. Partisipasi pemilih masyarakat kota Padang pada 
Pilkada 2013 hanya sekitar 50 sampai 55 persen. Angka itu jauh dari target KPU secara nasional yaitu 77,5 persen. KPU sebagai penyelenggara menjadi pihak yang paling bertanggung jawab untuk meningkatkan partisipasi pemilih itu, untuk itulah relawan demokrasi yang terdiri dari 20 orang siap diterjunkan untuk mensosialisasikan Pilkada ke tengah masyarakat.

Kota Padang juga memiliki jumlah kaum difabel yang banyak. Angka yang tinggi ini rupanya belum diantisipasi dengan pemerataan hakhak politik bagi kaum difabel. Selain kaum difabel, kaum marjinal di Kota Padang jumlahnya juga banyak. Namun tidak diiringi dengan pemberdayaan terhadap kaum marjinal. Program relawan demokrasi adalah gerakan sosial yang dimaksudkan untuk meningkatkan partisipasi dan kualitas pemilih dalam menggunakan hak pilih. Relawan demokrasi menjadi mitra KPU Kota Padang dalam menjalankan agenda sosialisasi dan pendidikan pemilih berbasis Kabupaten/Kota. Bentuk peran serta masyarakat ini diharapkan mampu mendorong tumbuhnya kesadaran tinggi serta tanggung jawab penuh masyarakat untuk menggunakan haknya dalam pemilu secara optimal. Di sisi lain, harus ada upaya untuk meningkatkan partisipasi dimana upaya antisipasi atas situasi kejenuhan dengan frekuensi penyelenggaraan pemilu yang tinggi, ketidakpuasan atas kinerja sistem politik yang tidak memberikan perbaikan kualitas hidup, maladministrasi penyelenggaraan pemilu, adanya paham keagamaan anti demokrasi, dan melemahnya kesadaraan masyarakat tentang pentingnya pemilu sebagai instrumen transformasi sosial, dan lain sebagainya.

Program relawan demokrasi muncul juga dilatarbelakangi oleh inflasi kualitas memilih. Tanpa mengabaikan apresiasi kepada pemilih yang menggunakan hak pilihnya secara cerdas, sebagian pemilih kita terjebak dalam pragmatisme. Tidak semua pemilih datang ke TPS atas idealisme tertentu tetapi ada yang didasarkan pada kalkulasi untung rugi yang sifatnya material, seperti mendapatkan uang dan barang-barang kebutuhan hidup sehari-hari.

Pragmatisme pemilih ini sebagian disumbang oleh tingkat literasi politik yang relatif rendah, melemahnya kesukarelaan masyarakat (voluntarisme) dalam agenda pencerdasan demokrasi, dan masifnya politik tuna ide dari kontestan pemilu. Pemilihan mesti menjadi titik balik persoalan partisipasi pemilih yang sebelumnya ada. Angka partisipasi memilih harus meningkat dan inflasi kualitas memilih harus dipulihkan bahwasanya memilih adalah tindakan politik yang mulia. KPU Sumatera Sarat komponen bangsa lainnya memiliki tanggung jawab yang besar untuk memastikan titik balik itu terwujud.

Pelopor-pelopor demokrasi akan dibentuk di setiap segmen yang kemudian menjadi penyuluh pada setiap komunitasnya. Segmentasi itu dilakukan dengan kesadaran bahwa tidak semua komunitas mampu dijangkau oleh program KPU Kota Padang. Selain itu segmentasi tersebut adalah strategis baik dari sisi kuantitas maupun pengaruhnya dalam 
dinamika sosial-politik berbangsa dan bernegara.

Program Relawan Demokrasi diharapkan mampu menumbuhkan kembali kesadaran positif terhadap pentingnya pemilu dalam kehidupan berbangsa dan bernegara. Pada akhirnya relawan demokrasi ini dapat menggerakan masyarakat tempat mereka berada, agar mau menggunakan hak pilihnya dengan bijaksana serta penuh tanggung jawab, sehingga partisipasi pemilih dan kualitas Pemilihan dapat lebih baik dibandingkan pemilu-pemilu sebelumnya.

\section{METODE PENELITIAN}

Jenis penelitian ini yaitu penelitian deskriptif kualitatif merupakan suatu penelitian yang menggambarkan atau melukiskan suatu peristiwa untuk diambil kesimpulan secara umum, yang mana pada penelitian ini menyangkut pada implementasi kebijakan program Relawan Demokrasi pada Pilkada 2018 di KPU Kota Padang. Lokasi yang menjadi tempat penelitian ini berfokus di KPU Kota Padang dan terbatas pada wilayah hukum Kota Padang. Oleh karena itu, lokasi tersebut menjadi objek penelitian peneliti. Informan penelitian adalah orang yang berpotensi dalam memberikan informasi yang sebenarnya. Di mana, informan yang menjadi sumber penelitian ini berasal dari unsur KPU Kota Padang dan Relawan Demokrasi KPU Kota Padang. Teknik Pengumpulan Data Dapat dilakukan melalui observasi, wawancara, dokumentasi dan studi kepustakaan.

\section{HASIL DAN PEMBAHASAN}

1. Implementasi kebijakan program relawan demokrasi oleh KPU Kota Padang dalam meningkatkan partisipasi politik masyarakat dalam pemilihan umum kepala daerah 2018 di Kota Padang.

Komunikasi kebijakan program relawan demokrasi pada pilkada 2018 kepada para petugas pelaksana dari KPU dan relawan demokrasi proses komunikasi telah terlaksana secara efektif.

Diperoleh sumber daya yang ada dibutuhkan dalam implementasi kebijakan program relawan demokrasi belum sepenuhnya dapat memberikan hasil yang maksimal, Karena berbagai alasan seperti tidak terlalu aktifnya beberapa kelompok pemilih. Tapi walaupun belum bisa memberikan hasil yang maksimal program relawan demokrasi ini sudah bisa meningkatkan partisipasi pemilih di kota Padang, dari yang hanya skitar $52 \%$ pada pilkada 2013 menjadi $64 \%$ di pilkada 2018 kenaikan yang lumayan signifikan dengan berbagai kendala yang di alami KPU dalam menjalankan program relawan demokrasi ini.

Relawan Demokrasi KPU Kota Padang mempunyai tingkat komitmen yang tinggi. Ini dikarenakan dari 20 (dua puluh ) orang yang terpilih untuk menjadi anggota Relawan Demokrasi absensi yang hadir dalam setiap rapat dan kegiatan bersama lintas segmen mencapai rata- rata 14 (Empat Belas) orang. Begitu juga pada saat pelaksanaan sosialisasi dan pendidikan pemilih hampir semua segmen sering penuh anggotanya bahkan bergantian dalam pembagian tugasnya. Adanya beberapa ketidakhadiran anggota Relawan Demokrasi lebih karena kendala 
jadwal kuliah, jadwal pekerjaan, serta kegiatan lain. Namun, adanya ketidakhadiran tersebut seringnya telah berkoordinasi terlebih dahulu pada koordinator masing masing segmen dan diteruskan kepada Ketua Relawan Demokrasi.

Struktur birokrasi yang menghubungkan antara KPU Kota Padang dengan Relawan Demokrasi tidaklah begitu rumit. Pertanggung jawaban Relawan Demokrasi diwakili oleh Ketua Relawan Demokrasi kepada Komisioner KPU Kota Padang yang mengepalai Divisi Sosialisasi, Pendidikan Pemilih, dan Humas, dan KPU Kota Padang berkoordinasi langsung dengan KPU Pusat. Program relawan demokrasi ini merupakan instruksi langsung dari KPU pusat dan tidak ada hubungan dengan lembaga pemerintah lain.

2. Faktor penghambat terlaksananya program relawan demokrasi dalam meningkatkan upaya partisipasi politik masyarakat

\section{Anggaran}

Dana operasional merupakan hal yang penting dalam meningkatkan kinerja Relawan Demokrasi. Dana tersebut bisa memperlancar kegiatan dalam mensosialisasikan pemilu, mengingat bahwa jauhnya jangkauan yang tidak bisa dijangkau oleh Relawan Demokrasi.

\section{Kompetensi}

Belum memadainya kompetensi yang dimiliki oleh Relawan Demokrasi. Meskipun Relawan Demokrasi direkrut dari Mahasiswa, LSM yang merupakan penyandang disabilitas ISM KPI ( Koalisi Perempuan Indonesia ) namun tidak memberikan jaminan untuk bisa memiliki kompetensi yang baik tertutama ketika berkomunikasi dengan kelompok sasaran

\section{Pelatihan Teknis Yang Kurang Memadai}

KPU melakukan pelatihan masih belum memadai kepada Relawan Demokrasi dan belum mampu memberikan Relawan Demokrasi tentang sosialisasi pemilu secara baik dan benar

\section{Sulit mendata disabilitas di suatu daerah}

Relawan Demokrasi sulit mendata dan mendapatkan informasi keberadaan penyandang disabilitas. Relawan Demokrasi hanya mengetahui penyandang disabilitas yang terdata di LSM.

\section{KESIMPULAN}

Relawan Demokrasi merupakan program nasional dari KPU RI yang dirancang untuk seluruh kbupaten/kota setempat. Relawan Demokrasi Kota Padang dilahirkan atas supervisi KPU Kota Padang dan bertujuan untuk meningkatkan kualitas dan kuantitas pemilih dalam menggunakan hak pilihnya.

Implementasi Kebijakan Program Relawan Demokrasi di Kota Padang bertujuan agar masyrakat Kota Padang bisa memberikan suaranya secara cerdas, sehingga bisa meminimalisir terjadinya fenomena suara tidak sah ketika pemilu dilangsungkan.

1. Implementasi kebijakan program relawan demokrasi oleh Kpu Kota Padang pada pilkada 2018 sudah berjalan dengan baik namun masih terdapat berbagai persoalan seperti insentif komunikasi yang masih kurang, Pelatihan teknis, Petunjuk pelaksana dan anggaran yang bisa dikatakan belum cukup 
untuk melaksanakan kebijakan program tersebut.

2. Faktor-faktor yang menjadi penghambat dalam mengimplementasikan kebijakan program relawan demokrasi oleh Kpu Kota Padang yang pertama adalah anggaran, yang kedua kompetensi, yang ketiga Pelatihan teknis yang kurang memadai dan yang terakhir adalah sulit nya mendata orang orang disabilitas di suatu daerah.

3. Namun, Menurut data yang diperoleh dari KPU Kota Padang, jumlah partisipasi pemilih di Kota Padang pada Pilkada 2018 menunjukkan peningkatan dibandingkan Pilkada 2013. Partisipasi pemilih pada Pilkada 2018 mencapai 64\% atau meningkat cukup banyak dibanding Pilkada 2013 yaitu sekitar 52 \%. Dengan melihat hasil tersebut, dapat dikatakan salah satu tujuan dari program Relawan Demokrasi untuk meningkatkan jumlah partisipasi pemilih khususnya di Kota Padang sudah berhasil, walapun belum bisa mencapai target dari KPU Pusat . Dengan demikian, program Relawan Demokrasi dapat direkomendasikan untuk dibentuk lagi pada masa Pilkada 2023.

\section{DAFTAR PUSTAKA}

Arifin, Anwar. 2011. Komunikasi Politik. Yogyakarta: Graha Ilmu

Budiardjo, Miriam, 2008. Dasar-Dasar Ilmu Politik. Jakarta: PT Gramedia Pustaka Utama

Damsar. 2010. Pengantar Sosiologi Politik. Jakarta: Kencana
Efriza, 2012. Political Explorer Sebuah Kajian Ilmu Politik, Jakarta: Alfabeta.

Gartiria Hutami, Pengaruh Konflik Peran Dan Ambiguitas Peran Terhadap Komitmen

Independensi Auditor Internal Pemerintah Daerah (Studi Empiris Pada Inspektorat Kota Semarang) (Universitas Diponegoro, Jurnal).

Subiakto, Henry. Rachmah Ida. 2015. Komunikasi Politik, Media, dan Demokrasi. Jakarta: Prenadamedia Group

Manik, Husni Kamil, dkk. 2013. "Surat Edaran KPU RI No. 609/KPU/IX/2013".Jakarta:

Sekretariat KPU RI.

Manik, Husni Kamil. 2013. "Petunjuk Pelaksanaan Program Relawan Demokrasi 2014 KPU RI".Jakarta: Sekretariat KPU RI.

Nugroho, Riant. 2013. Kebijakan Publik : Formulasi, Implementasi dan Kebijakan. Jakarta: Gramedia. Bungin, Burhan. 2005. Metodelogi Penelitian Kualitatif. Jakarta: Kencana

Muhammad Fuad, Zamzam, 2015. "Peran Pemuda Relawan Demokrasi Dalam Meningkatkan Partisipasi Politik Masyarakat Pada Pemilihan Umum Legislatif Tahun 2014 Dan Implikasinya Terhadap Ketahanan Politik Wilayah (Studi Pada Relawan Demokrasi Banyumas, Jawa Tengah)" Jurnal Ketahanan Nasional, XXI

Febriantanto, Pangky, 2018. "Implementasi Kebijakan Program Relawan Demokrasi Pada Pemilu 2014 di KPU Kota Yogyakarta" Jurnal Kajian Ilmiah Universitas Bhayangkara Jakarta Raya

Moleong, L. J. 2008. Metodologi Penelitian Kualitatif. Bandung: Remaja Rosdakarya. 
Zamroni. 2000. Pendidikan Untuk Demokrasi. Yogyakarta: BIGRAF Publishing.

Efriza dan Rohaniyah, Yoyoh. 2012. Pengantar Ilmu Politik Kajian Mendasar Ilmu Politik. Malang: Intrans Publishing.

Rush, Michael dan Phillip Althoff. 2005. Pengantar Sosiologi Politik. Terjemahan Dr. Kartini Kartono. Jakarta: PT Raja Grafindo Persada.
Yusuf, M Pawit. 2010. Komunikasi Instruksional Teori $\mathcal{E}$ Praktik. Jakarta: PT Bumi Aksara. 